Watts Robyn (Orcid ID: 0000-0002-3526-7261)

Gawne Ben (Orcid ID: 0000-0002-4850-2144)

\title{
Learning from concurrent adaptive management in multiple catchments within a large environmental flows program in Australia
}

\author{
Running Title \\ Concurrent adaptive management in a large environmental flows program
}

Robyn J. Watts ${ }^{1}$, Fiona Dyer ${ }^{2}$, Paul Frazier ${ }^{3}$, Ben Gawne ${ }^{2}$, Paul Marsh ${ }^{4}$, Darren S. Ryder ${ }^{5}$, Mark Southwell ${ }^{5}$, Skye M. Wassens ${ }^{1}$, J. Angus Webb ${ }^{6}$, Qifeng $\mathrm{Ye}^{7}$

${ }^{1}$ Institute for Land Water and Society, Charles Sturt University, Albury, Australia

${ }^{2}$ Institute for Applied Ecology, University of Canberra, Canberra, Australia

${ }^{3}$ 2rog Pty. Ltd., Armidale, Australia

${ }^{4}$ Commonwealth Environmental Water Office, Canberra, Australia

${ }^{5}$ Ecosystem Management, University of New England, Armidale, Australia

${ }^{6}$ Department of Infrastructure Engineering, The University of Melbourne, Melbourne, Australia

${ }^{7}$ South Australian Research and Development Institute, Adelaide, Australia

\section{Correspondence}

Robyn Watts. Institute for Land Water and Society, Charles Sturt University, Albury, 2640, Australia Email: rwatts@csu.edu.au Phone: +61 260519807

\section{Acknowledgements}

This paper arose from an Adaptive Management Forum held in 2017 to share learnings across the Australian Government's Long-Term Intervention Monitoring program (LTIM), a large collaborative project funded by the Australian Department of Environment and Energy. We are grateful to water managers from the Commonwealth Environmental Water Office, state and regional management agencies and community members for sharing their wisdom with us. We would also like to thank the members of LTIM Monitoring and Evaluation teams who have shared their learning and experiences of environmental flows with us over many years.

\begin{abstract}
Adaptive management is central to improving outcomes of environmental water delivery. The Australian Government's Murray-Darling Basin (MDB) Plan 2012 explicitly states that adaptive management should be applied in the planning, prioritisation and use of environmental water. A Long Term Intervention Monitoring (LTIM) program was established in 2014 to evaluate responses to environmental water delivery for seven Areas within the MDB, with evaluation also undertaken at the Basin scale. Adaptive management at the Area scale was assessed using two approaches: 1) through a reflective exercise undertaken by researchers, water managers and community members,

This is the author manuscript accepted for publication and has undergone full peer review but has not been through the copyediting, typesetting, pagination and proofreading process, which may lead to differences between this version and the Version of Record. Please cite this article as doi: $10.1002 /$ rra.3620
\end{abstract}

This article is protected by copyright. All rights reserved. 
and 2) through an independent review and evaluation of the program, where relevant reports were reviewed and managers and researchers involved in the LTIM program were interviewed. Both assessment approaches revealed that the scale of management actions influenced the extent to which learnings were incorporated into subsequent actions. Although there were many examples where learnings within an Area had been used to adaptively manage subsequent environmental water deliveries within that Area, there was inconsistent documentation of the processes for incorporating learnings into decision making. Although this likely limited the sharing of learnings, there were also examples where learnings from one Area had influenced environmental water management in another, suggesting that sharing between concurrent projects can increase learning. The two assessments identified ways to improve and systematically document the adaptive management learnings. With improved processes to increase reflection, documentation and sharing of learnings across projects, there is an opportunity to improve management of environmental water and ecosystem outcomes.

\section{Keywords}

environmental water, adaptive management, social learning, uncertainty, decision-making, monitoring and evaluation, Murray-Darling Basin

\section{Introduction}

Freshwater systems are experiencing ongoing pressure from human populations, with the flow regimes of most large rivers being highly altered and ecosystems becoming increasingly degraded (Dudgeon et al., 2006). Large-scale management programs are increasingly being implemented to improve the ecological condition of rivers. Across the world several large programs, such as the Sustainable Rivers Project in the U.S. (Warner et al., 2014) and the European Water Framework Directive (Acreman \& Ferguson, 2010), have sought to maintain and restore freshwater ecosystems through a combination of actions including the delivery of environmental water. In the Murray-Darling Basin (MDB) in Australia the Murray-Darling Basin Plan 2012 (the Basin Plan) provides a high level framework that sets standards for governments and agencies to manage the Murray-Darling Basin's water resources in a coordinated and sustainable way in collaboration with the community to provide for integrated management of the Basin water resources to achieve a healthy and working Murray-Darling Basin (Australian Government, 2012b). Large programs such as these usually refer to the need to manage water adaptively and to enable adaptive management in relation to the planning and implementation of the programs.

Adaptive management is an approach that enables managers working in complex natural resource management settings to learn by doing (Holling, 1978). It is an alternative to conventional management, in that adaptive management enables effective action to occur in the presence of uncertainty (Webb et al., 2017). Adaptive management provides a means by which managers can 
implement management decisions using available knowledge, and adapt their management practises as new information and learning emerges, especially from the management actions previously implemented. This allows decision making to proceed, despite uncertainty about the impacts of management actions (Webb et al., 2017). It is not a 'trial and error' approach but is purposeful and deliberate (Allan \& Stankey, 2009) and structured (Pahl-Wostl et al., 2010). The concept of adaptive management is often included in the guiding documents for large programs. For example, in the Basin Plan in Australia there are numerous statements about using an adaptive approach to incorporate improvements in knowledge to provide for continuous improvement in the adaptive management of water resources (Australian Government, 2012b). In section 1.07 of the Basin Plan the term adaptive management is taken to include a) setting clear objectives, b) linking knowledge (including local knowledge), management, evaluation and feedback over a period of time, c) identifying and testing uncertainties, d) using management as a tool to learn about the relevant system and change its management, e) improving knowledge, and f) having regard to the social, economic and technical aspects of management. Although the concept of adaptive management has been the focus of considerable discussion in the literature, until recently there were few documented examples of adaptive management of environmental water delivery and few details describing how adaptive management has been achieved. This may be a reflection of limited adaptive management practises occurring, because the implementation of major environmental programs have generally lagged behind policy (Harwood et al., 2017; Le Quesne et al., 2010). However, the lack of documented examples of adaptive management of environmental water delivery is also due to the under-reporting of adaptive management successes and failures (McFadden et al., 2011; Allan \& Watts, 2018). Webb et al. (2018) reported that a search of the Web of Science in mid-2017 identified only 73 publications mentioning adaptive management of environmental flows, with nearly all of these studies published since 2010. A special issue on adaptive management of environmental flows in Environmental Management (Webb et al., 2018) added several more examples. In most cases, advances in enacting the practise of adaptive management remained within a project group and may not have influenced practices in other systems. One of the major challenges in environmental water management is to increase the documentation of adaptive management, so that benefits of learning extend beyond the system where the project is undertaken (Webb et al., 2018).

To facilitate exchange of learning to other catchments and regions, it is informative to document the process of adaptive management, rather than simply documenting the ecosystem outcomes of changed management actions. In addition, the extent of learning can be demonstrated by changes in behaviours or attitudes that become situated in wider communities of practice and networks (Reed et al., 2010; Peat et al., 2017). Allan and Watts (2018) document an example of social learning associated with environmental watering in the Edward-Wakool system in the MDB. They describe the processes for exchange of knowledge among managers, scientists and the community, how this 
changed the understanding of the individuals, agencies and communities of practice involved in the project, and how that resulted in changed management practices. While Allan and Watts (2018) refer to pathways for stakeholders not directly involved in the project to learn from these actions ('Outer learning loops'), the impact of sharing these learnings with others outside the immediate project team was not fully explored. Sharing lessons about the processes of adaptive management allows managers and practitioners working in other areas to improve their own management practices. However, there is often no formal process to share learnings among different projects. In this paper we examine the hypothesis that better outcomes of environmental water management can be achieved when there are processes for sharing learning across concurrent projects. To do this we examine a case study of the Long Term Intervention Monitoring (LTIM) program implemented by the Australian government from 2014 to 2019 to monitor and evaluate outcomes of environmental water delivery and provide input to the adaptive management of environmental water (Department of Environment and Energy, 2019). Monitoring under this program was undertaken concurrently in seven Selected Areas (hereafter referred to as Areas), with results synthesised at the whole-of-basin scale (Gawne et al., 2013; Gawne et al., this issue). This paper focusses on the learning and adaptive management of environmental water at the Area scale. This program provided an opportunity to examine how learnings from one Area can directly influence the adaptive management of environmental water in another Area. We discuss the range of approaches used to share learnings within and among concurrent projects and describe how water was adaptively managed at different spatial and temporal scales.

\section{Environmental water delivery under the Murray-Darling Basin Plan}

The MDB covers an area of approximately one-seventh of the Australian continent and incorporates three of the longest rivers in Australia (Murray, Murrumbidgee and Darling Rivers) and more than 30,000 wetlands, of which sixteen are listed as internationally important under the Ramsar Convention. The MDB includes approximately $50 \%$ of Australia's irrigated agriculture, making an important contribution to the Australian economy. Water resources in the MDB have been extensively developed, resulting in declining condition of rivers, wetlands and water dependent ecosystems (Kingsford, 2000; Davies et al., 2008; MDFRC 2011).

The Basin Plan legislation came into effect in November 2012 with the aim to deliver a 'healthy working basin' with healthy and resilient ecosystems, productive and sustainable water-dependent industries and vibrant communities (Swirepik et al., 2016). Following recognition that the MDB's water resources were over-allocated, the Basin Plan set environmentally sustainable diversion limits (SDLs), aiming to return an average of $2750 \mathrm{GL}$ per year of water from consumptive use to the environment. This was to be achieved through improvement to irrigation infrastructure and the purchase of water entitlements from irrigators who decided to sell some or all of their entitlement to the Australian Government (Commonwealth of Australia, 2011). The water licenses are governed 
by rules defined in catchment water sharing plans and the Commonwealth water holdings must be managed within these existing rules, which present both opportunities and constraints (Banks and Docker, 2014). An independent statutory office holder, the Commonwealth Environmental Water Holder (CEWH), was also established. The CEWH manages the Commonwealth's environmental water holdings and, in collaboration with state partners, uses environmental water to address environmental needs and achieve Basin Plan objectives. The physical delivery of Commonwealth environmental water is managed by state water delivery agencies across the Basin. Restoration of parts of the flow regime is a key feature of environmental flow delivery and institutional arrangements governing environmental flows can influence the ability of managers to respond to achieve ecosystem outcomes (Banks and Docker, 2014).

The Basin Plan explicitly states that adaptive management should be applied in the planning, prioritisation and use of environmental water. The Murray-Darling Basin Authority (MDBA) develops annual environmental watering priorities, whereas planning at the catchment scale is predominantly undertaken collaboratively by the Commonwealth Environmental Water Office (CEWO, which supports the $\mathrm{CEWH}$ ) and state government agencies that work in a complex collaborative environment with diverse stakeholders. All Areas also have some form of water delivery committee involving multiple agencies. A framework to assess options for environmental water use (CEW 2011) outlines ecological and management objectives for different water availability scenarios. The first water entitlements were acquired by the CEWH in 2008, and as water availability improved and more licences were acquired, options for water delivery expanded from small actions at individual sites involving small volumes of water through to multi-site actions (Docker and Robinson, 2014). The water managers have faced a number of challenges to deliver environmental water to target sites because there are physical constraints in the system, existing operating rules that make it difficult for environmental water holders to supplement natural flows, and there are challenges associated with protecting water left in stream (Docker and Robinson, 2014). Early approaches to water delivery suggested there were real environmental gains made within the context of a highly regulated river system, however water managers noted that continued intergovernmental cooperation and effort will be required for many years to come to achieve optimal social, economic and environmental outcomes (Docker and Robinson, 2014).

\section{The Long Term Intervention Monitoring program}

In 2014 the Australian government, through the CEWO, established the Long Term Intervention Monitoring (LTIM) program to address the requirements under the Water Act 2007 and the MDB Plan. This program was initially funded from 2014 to 2019 and was extended until 2022 (CEWO, 2019a). The aims of the LTIM program were to: evaluate the contribution of Commonwealth environmental water to the objectives of the MDBA Environmental Watering Plan; evaluate the ecological outcomes of Commonwealth environmental watering; infer ecological outcomes of 
Commonwealth environmental watering in areas of the MDB that are not monitored; and support the adaptive management of Commonwealth environmental water. Hart and Butcher (2018) in their review of the LTIM program, state that this program was ambitious and world-leading in its scope, both spatially and temporally, and the aim to assess the effectiveness of environmental water delivery in achieving local and Basin scale outcomes has never been attempted before anywhere in the world.

Monitoring and evaluation for the LTIM program was focused on seven Areas within the MDB that are high value aquatic ecosystems (Figure 1). These Areas were those most likely to receive environmental water during the five year project (Gawne et al., this issue). Two of the Areas (Gwydir and Warrego) are located in the northern MDB and five Areas (Lachlan, Murrumbidgee, EdwardWakool, Goulburn and Lower Murray) are in the southern MDB (Figure 1). Environmental water management in the Gwydir, Warrego, Lachlan, Murrumbidgee and Goulburn Areas is undertaken by a primary state agency in conjunction with the CEWO. Environmental water management in the Edward-Wakool and Lower Murray Areas involves the state government agencies as well as the Murray-Darling Basin Authority (MDBA) in conjunction with CEWO.

The conceptual framework of the LTIM program involves an objectives hierarchy, conceptual models, identification of major flow types and their ecological role, and a range of water availability scenarios (Gawne et al., this issue). This conceptual framework was used to select indicators that were considered to respond to environmental water in a predictable manner. Basin-scale indicators were monitored across all Areas using standard methods, and local-scale indicators were monitored to answer questions specific to environmental water delivery in those Areas. Consequently, a different suite of indicators was monitored in each of the seven Areas (Table 1) because of different hydrology, habitats and local priorities. As the Gwydir, Warrego, Lachlan and Murrumbidgee systems include large wetland complexes and the delivery of environmental water in these Areas is focussed on these assets, many of the local-scale indicators were developed to monitor wetland and floodplain habitats (Table 1). In the Edward-Wakool, Goulburn and Lower Murray Areas there are constraints to the delivery of water overbank or outside the channel, so environmental watering actions are largely focussed on the delivery of in-channel flows. In these three Areas several localscale indicators were monitored within the river channel and on riverbank environments (Table 1).

Monitoring and evaluation in the seven Areas was undertaken by independently contracted, multidisciplinary monitoring and evaluation teams, involving universities, state government agencies and consultants. The seven Area project teams work independently and under separate funding contracts and reporting arrangements. However, there was a single set of data standards and structures for recording data, and the data files were stored in a central data management system to enable a whole of basin evaluation to be undertaken by a separately contracted basin evaluation team. 


\section{Adaptive management in the LTIM program}

The learning and adaptive management of environmental water at the Area scale within the LTIM program was assessed using two approaches. Firstly, the adaptive management approach was described and evaluated through a reflective exercise at an Adaptive Management Forum in 2017 by research scientists from each of the seven LTIM teams along with water managers from Australian federal, state and regional management agencies and community members. The aims of the forum were to 1) share examples of how LTIM monitoring has supported adaptive environmental water management, 2) assess similarities and differences in adaptive management among Areas and any emergent lessons, and 3 ) better understand the needs of environmental water managers. The adaptive management framework described in Eberhard et al. (2009), Watts et al. (2010) and Webb et al. (2017) was used to describe the process of learning and adaptive management in the LTIM program. This framework describes three distinct cycles of feedback and social learning (Figure 2). These three cycles reflect different ways in which learnings from environmental watering actions in the seven Areas have influenced the adaptive management of environmental water in the MDB. Learnings that occur between major formal planning reviews that result in small changes to strategies, plans, actions or monitoring are referred to as the inner learning loops (Figure 2). For example, these may be learnings from monitoring that influence the adaptive delivery of environmental water during the progress of a watering action. Learnings that inform the next formal phase of planning and implementation are shown as the main learning cycle (plan-do-monitor-learn) (Figure 2). For example, monitoring and evaluation within each Area have influenced the adaptive management of water through the modification of subsequent annual and five-year water plans for that Area. Innovations and learnings that are shared with practitioners and stakeholders outside a project that may influence practices, annual water planning or watering actions in other systems are referred to as outer learning loops (Figure 2).

The evidence for, and effectiveness of, adaptive management within the LTIM program was also assessed by independent consultants as part of a mid-term review and evaluation of the program (Hart and Butcher, 2018). The consultants reviewed relevant reports and interviewed managers and researchers involved in the LTIM program to assess the progress, effectiveness, achievements and outputs of the program based on the first three years of monitoring.

Inner learning loops: Informing adaptive delivery of environmental water during the progress of watering actions

Through a reflective exercise at an Adaptive Management Forum in 2017 and subsequent reflection within Area teams we found there was good evidence that inner loop learning had influenced adaptive management of water in all seven LTIM Areas (Table 2). The independent review of the LTIM program commented that "There are some excellent interactions between the Selected Area

This article is protected by copyright. All rights reserved. 
and CEWO Delivery teams that are resulting in a considerable number of learnings that are being translated into better management of the Commonwealth's environmental water". The review also noted that all of the Area teams had given considerable attention on the capture of adaptive management learning's each year (Hart and Butcher 2018), however this could be done more systematically.

The reflective exercise at the Adaptive Management Forum identified a number of processes that had facilitated learning within the seven Areas (Table 2 ) to be made in real time during the implementation of environmental watering actions. This learning had resulted in small changes to strategies, plans and practices. The real-time learning was facilitated by regular project team meetings or communications, where results of monitoring were shared and reflected on. For example, monitoring results were shared by researchers in the LTIM Area teams during regular (often every two weeks) meetings with federal and state environmental water managers. At times when there were critical decisions to be made, additional informal teleconferences or meetings enabled monitoring results to be shared immediately with water managers (Table 2). Hart and Butcher (2018) commented that this close interaction between the CEWO water delivery teams and the Area teams had provided practical scientific information and advice on the relationships between flow components and possible ecological outcomes in a timely manner, mostly well ahead of formal reporting timelines, and this had resulted in improved decision-making regarding particular environmental watering events. In some Areas (e.g. Edward-Wakool Area) early results were also presented to community members affected by watering actions (Table 2 ) and these discussions resulted in water managers modifying watering actions to maximise environmental outcomes while considering potential community impacts.

These processes for rapid sharing of results enabled environmental water managers to modify watering plans when the environmental watering action had already commenced. The evidence of this adaptive learning was not consistently documented across the different Areas. Evidence of the learnings was spread across annual environmental water planning documents, environmental water use option reports and monitoring reports that are publically available on government websites (e.g. CEWO, 2019b). For example, each of the Edward-Wakool annual LTIM reports provided comments on adaptive management in the recommendations section of the report (e.g. Watts et al, 2015). In some cases evidence was available in stakeholder committee minutes that are not publically available and also some evidence and examples were documented in refereed papers (e.g. Allan and Watts, 2018; Watts et al., 2018). For example, the Edward-Wakool LTIM team provided an update of monitoring outcomes to the Edward-Wakool Operational Advisory Group every two weeks following each monitoring trip. This real-time reporting enabled water managers to modify watering actions as they were underway. For example, the commencement date of the recession of an environmental flow during a spring/early summer watering action was adaptively managed based on fish larvae 
monitoring results, to ensure the recession commenced after Murray cod (Maccullochella peelii) larvae had ceased drifting, thus minimising the risk of spawning nests being exposed during flow recession (Allan \& Watts, 2018).

Another example of inner loop learning during the LTIM program is demonstrated through the adaptive management of environmental water in the Murrumbidgee Area. The lower Murrumbidgee floodplain is a key waterbird foraging and breeding area, supporting species listed under bilateral migratory bird agreements with Japan (JAMBA), China (CAMBA) and the Republic of Korea (ROKAMBA) (Kingsford \& Thomas, 2004). Large breeding colonies typically establish at multiple locations across the floodplain following un-regulated flows, and in the past two decades substantive breeding colonies (> 10,000 individuals) have established on three occasions (2005, 2011-12 and 2016) with the largest colony of over 60,000 pairs in 2011-12 (Brandis et al., 2011; Wassens et al., 2018). While the triggers for waterbird breeding were natural flooding events, in all cases environmental water was delivered after the commencement of the natural flood event to maintain appropriate water depths for the breeding colonies. This prevented nest abandonment and created suitable foraging habitats to support fledgling survival. Monitoring of the 2016 event through the LTIM program by on-ground teams, aerial surveys and landholders was used to identify colonies as they established. This information was used by the Waterbird Technical Advisory Group (TAG) (including representatives from the CEWO, NSW Department of Planning, Industry and Environment, Water NSW, researchers and land managers) to develop plans to support key colonies and arrange on-ground logistics for water delivery. Monitoring of egg and chick development along with water levels and water quality was shared directly with the TAG who used the information to plan additional top up watering, if required, to complete the breeding event (Wassens et al., 2018). A similar adaptive management process to this described here in the Murrumbidgee Area also occurred in the Lachlan Area (Dyer et al., 2017).

Main learning loop: Contribution to annual and long-term goals and plans in response to learning

The reflective exercise at the 2017 Adaptive Management Forum identified examples and processes that had contributed to adaptive management at annual and longer-term time scales, resulting in changes and improvements in longer-term watering plans. Across all of the seven Areas there was evidence that reflection, learning and exchange of information at the end of each watering year enabled learnings to be incorporated into the annual planning for the subsequent year and to contribute to 5-year water planning processes (Table 2). The processes to facilitate this 'main learning cycle' (Figure 2) included meetings with environmental water managers and Environmental Water Advisory Groups at the end of each evaluation cycle, and reflection and discussions at an annual environmental water planning workshop held for each Area (Table 2). These planning workshops usually involved a range of stakeholders (e.g. Allan \& Watts, 2018). Similar to the inner 
loop learning, the evidence of this main loop adaptive learning was not consistently documented across the different Areas. Evidence of the learnings is available in annual environmental water planning documents and monitoring reports that are publically available on government websites (e.g. CEWO 2019b), stakeholder committee minutes that are not publically available, or in some cases has been documented in refereed papers (e.g. Alan and Watts, 2018).

There is evidence that the social learning that occurred as part of this main learning loop has influenced adaptive management of water in all seven LTIM Areas (Table 2). For example, in 2013 an in-stream environmental fresh event was delivered down several of the distributary channels in the lower Gwydir catchment primarily to support native fish movement and spawning (Southwell et al., 2015). While environmental water was delivered as a separate flow pulse in the upper reaches of the channels, it was soon impacted by irrigation water deliveries and the distinct 'pulse' hydrograph shape was lost. Monitoring showed that where the hydrograph pulse remained distinctive, there was bony herring (Nematolosa erebi) spawning, but when the flow pulse was flattened, spawning was not recorded. As a result of this learning, a flow pulse was delivered in 2014 with care taken to keep the pulse separate from irrigation deliveries. The flow pulse was delivered as a discrete flow event consistent with the hydrograph shape ordered, however, no fish spawning or successful recruitment was observed. While this is an example of learning influencing subsequent management, it also highlights the variable nature of biotic response to flow, with multiple factors (other than flow) can affect responses. Rather than specifically targeting fish spawning, in-stream environmental freshes in the Gwydir system are now planned and delivered with an emphasis on reinstating hydrologic variability, and priming the system early in the water year to provide favourable conditions for riverine species throughout the year.

Annual and long-term environmental watering plans in the Goulburn Area have also been underpinned by reflection, learning and exchange of information from the monitoring and evaluation program. An annual workshop is held in approximately February each year to present results from the previous year's monitoring to inform water planning for the year ahead. The workshop is attended by the monitoring team, local water managers, state water and environment managers, and the CEWO. Monitoring results are discussed to assess their implications for the seasonal watering proposal being prepared at that time of year. That document presents priorities for environmental water delivery for the upcoming water year, and is the framework within which individual watering decisions are made. Much of the discussion centres on the duration, frequency and timing of a 'spring fresh' as one of the major environmental water delivery events each year. Spring freshes delivered earlier in the year favour riverbank vegetation responses, while later freshes stimulate spawning by golden perch (Macquaria ambigua) (Webb et al., 2019). One adaptive outcome of the workshops has been that managers no longer attempt to achieve both vegetation and golden perch outcomes by providing a spring fresh in the middle of spring. Rather, consultation 
and consideration of prior year outcomes for environmental water are used to identify the priority ecological endpoint for the upcoming year and the spring fresh is designed accordingly (GBCMA, 2017).

Another example of main learning loop adaptive water management is the delivery of environmental water to create refuge areas for fish during hypoxic black water events (hypoxic water caused by excessive bacterial respiration of organic matter) in the Edward-Wakool system. Following a critical hypoxic blackwater event in 2010-11 that caused thousands of fish deaths, a synthesis of water quality data, fisheries survey data, a database of fish deaths, and community observations (Hutton, 2017; Watts et al., 2018) resulted in improved understanding of ecosystem responses to environmental water delivery during hypoxic blackwater. This learning was used to guide the planning of environmental watering actions during a subsequent hypoxic blackwater event in 2016 (Allan \& Watts, 2018).

Outcomes from LTIM program have also contributed to several long-term watering plans in these catchments. For example, in New South Wales the LTIM results from the Gwydir, Warrego, Murrumbidgee, Lachlan and Edward-Wakool LTIM projects have contributed to long-term watering plans (NSW OEH, 2018). These plans are bringing together local, traditional and scientific knowledge to develop plans for catchments across NSW, setting objectives for five, 10 and 20 year timeframes to guide the management of environmental water over the longer term (NSW OEH, 2018). Similarly, in South Australia, data and scientific knowledge developed from LTIM and other research and monitoring projects, have informed the development of ecological objectives, targets and environmental water requirements for the long-term environmental watering plan for the South Australian River Murray Water Resource Plan Area (SA Department for Environment and Water, 2017). This plan builds on many years of annual environmental water planning, and integrates the learnings and information developed through many long-running monitoring and research projects and programmes, including the LTIM program. The contribution of learnings from the LTIM project to these long-term Water Resource Plans was not specifically an intended outcome of the LTIM program, but was an un-anticipated by-product of the project that arose through relationships and partnerships that developed over time.

The independent review of the LTIM program (Hart and Butcher, 2018) also noted that a positive outcome of the LTIM Project at the Area-scale was the significant contribution being made to the adaptive management of water planning and delivery at the Area-scale. Hart and Butcher (2018) were of the opinion that this aspect of the project has had considerable benefits for the management of Commonwealth environmental water.

Outer learning loops: Learnings shared outside Areas influencing water plans elsewhere 
One of the interesting and innovative aspects of the LTIM program is that there were opportunities for learnings from each Area to be shared with teams managing and monitoring environmental water concurrently in other Areas (Table 3). Even though the seven Areas were all part of the broader LTIM program, we consider the sharing of learnings across Areas to be examples of outer learning loops, because there were different water managers involved in planning and water delivery and different researchers undertaking the monitoring and evaluation in the seven Areas. The processes to facilitate learning across Areas included teleconferences among LTIM Area Project Leaders, an LTIM Annual Forum and the LTIM Adaptive Management Forum held in 2017 (Table 3). The governance within CEWO also supported exchange of learnings across Areas. The CEWO structure has three water delivery teams (northern, central, and southern MDB) that plan and environmental watering actions. These teams share learnings within the CEWO office and through state water planning processes (Table 3). There was also opportunities for exchange of learnings through the Southern Connected Basin Environmental Water Committee (SCBEWC), an inter-agency committee involving the MDBA, CEWO and agencies from New South Wales, Victoria and South Australia to facilitate coordinated environmental water management in the southern MDB. Exchange of learnings was also facilitated through LTIM project thematic workshops. One workshop involved researchers from the Warrego, Gwydir, Lachlan and Murrumbidgee Areas sharing learnings from wetland and floodplain monitoring, while another workshop undertaken in January 2018 involving researchers from the Edward-Wakool, Goulburn, and Lower Murray Areas sharing learnings about river channel hydraulics (Table 3). Similar to the inner loop learning and the main loop learning, the evidence of this outer loop adaptive learning among Areas was not always publically available because it was documented in workshop summary reports, meeting notes or power-point presentations. In some cases the shared learning across Areas has been documented in annual reports to the CEWO (e.g. Dyer et al., 2016) and incorporated in planning activities.

The processes for outer loop learning for sharing information across Areas was unstructured and generally less systematic than processes for learning within Areas. Furthermore, sharing of information did not occur for all indicators. It was typically driven by individual researchers and water managers who took opportunities to use information from other Areas to help inform watering actions or interpret outcomes in the Area they were managing. For example, in 2015-16 environmental water was delivered in the Lachlan River system targeting golden perch movement and spawning. The hydrograph was designed with input from staff from NSW DPI fisheries and incorporated one small peak followed by a larger peak once water temperatures exceeded $23^{\circ} \mathrm{C}$ (Dyer et al., 2016). These conditions were thought to be optimal for golden perch spawning. However, there was no evidence of golden perch spawning, from either the monitoring of larval fish or efforts to detect young-of-year golden perch the following year. A subsequent systematic analysis of monitoring data and reports from other Areas, along with published studies was used to suggest reasons for the lack of spawning of golden perch in the Lachlan Area. In particular, learnings from 
the Goulburn Area that spawning of golden perch was greatest after several days of combined increases in flow and water temperature led to recommendations that subsequent watering actions in the Lachlan for golden perch outcomes needed to manage environmental water to achieve concomitant flow and temperature increases.

The processes for the systematic exchange of learning among Areas wasn't well embedded at the initial stage of the LTIM program. If there had been a clear process for sharing learnings established in the early years of the program, the results from multiple Areas may have better informed some watering actions earlier. For example, the processes for planning golden perch breeding events in the Goulburn Area could have better informed water delivery in the Lachlan Area earlier in the program. Over time, the value of devoting time and resources to sharing of learnings across the concurrent programs and increasing the pace of learning was recognised and the CEWO provided additional resources to support collaboration. This increased opportunities in the seven concurrent projects to enhance learning. Under this program there was the opportunity to test hypotheses in different systems, thus providing a degree of replication that is rarely achieved when delivering environmental water.

There is the potential that learnings from the LTIM program have influenced environmental flows projects or biodiversity and conservation policies elsewhere, however at this stage we have no concrete evidence that this form of outer loop learning has occurred. This outer loop learning could have occurred through researchers or managers of other environmental flow programs acting on findings from technical reports that are publically available on the CEWO website (CEWO, 2019b) or reading published journal papers on the LTIM program. In addition, it is possible that presentations on the LTIM program given at national and international conferences may have influenced programs elsewhere.

\section{Lessons learned}

This analysis of adaptive management within and among LTIM projects revealed that the scale of management actions (small actions at individual sites involving small volumes of water, through to larger multi-site actions) had a strong influence on the extent to which learnings were incorporated into subsequent management actions.

There were many examples where learnings from environmental watering actions within an Area had been used to adaptively manage subsequent watering actions within that same Area. This inner learning loop seemed to work well for single watering actions, where rapid response, real-time information and input to water management decisions occurred regularly. This is because the processes for sharing learnings within monitoring teams within local Areas were well established, and there were frequent opportunities for exchange of information. Each of the seven Area teams 
include mechanisms for interactions among scientists, water managers, and local communities to support the delivery and monitoring of environmental water. LTIM teams worked closely with local, Commonwealth, state and regional water managers to assist with planning, delivery and evaluation of environmental water. This type of learning is a key success of the LTIM program.

The input of learnings into longer term adaptive management cycles (main learning loop) was variable but all Area teams provided evidence that they had contributed to annual watering plans and reviews of long-term watering plans relevant to their Area. The level of success and effectiveness of teams to contribute to long-term watering plans differed due to geographical and stakeholder differences, habitat diversity and different level of complexity regarding water sources and flow management. The longer history of monitoring of environmental water prior to the LTIM program (e.g. in the Murrumbidgee, Edward-Wakool, Gwydir and Goulburn and lower Murray River Areas) may have also influenced the effectiveness of the different Area teams to contribute to longterm water planning. Adaptive management may have been easier in Areas with a longer history of monitoring, not only because of the availability of longer-term data sets, but also because the extended history of collaboration meant that scientists, managers and the community have had the opportunity over a longer-time frame to develop trusting partnerships and an understanding of the system.

Although the biophysical responses to environmental water within an Area were well documented, there was inconsistent documentation of the process for incorporating learnings into decision making. For example, in the Edward-Wakool system, where the evidence for learning has been evaluated by Allan and Watts (2018), it was found that the documented evidence of learning and adaptive management was spread across a number of environmental water planning documents, environmental water use option reports, monitoring reports, stakeholder committee minutes, and refereed papers. This reflected the circumstances in most Areas. Through the reflective exercise undertaken in $\mathbf{2 0 1 7}$ we found there was usually no single document that described and provided evidence of the process of adaptive management, nor was there a document with the specific lessons and shared understandings that have led to practice change. This highlights the need for normalising the process of identifying and articulating the social learning and change that occur during environmental watering actions. In the mid-term review of the LTIM program Hart and Butcher (2018) also noted that there was a need for better documentation of the many informal and formal discussions that led to changes in water delivery. Recommendation number 18 in their report (Hart and Butcher, 2018) stated "that the capture of adaptive management learning's be improved and done more systematically, in particular with the development of an accessible and searchable database to contain the learning's, and the production of an annual report that syntheses how this increased knowledge is changing the way in which environmental water is being delivered". 
Despite the deficiencies in documenting social learning and adaptive management of environmental watering actions within Areas, there were examples where learnings from one Area had been shared and influenced watering actions in another Area. Even when learnings and processes were not formally documented, they were shared though other processes such as annual workshops, thematic workshops and teleconferences. These mechanisms for sharing among Areas were possible because the seven LTIM projects were concurrent projects funded through a single large program. There were, however, some missed opportunities for sharing learnings. Although the process for exchange of learnings among Areas wasn't very well considered in the early stages of the LTIM program, over the course of the program all participants realised the importance of sharing learning and worked together to find ways to achieve it. Hart and Butcher (2018) noted that the management of the project adapted over time from a very 'top-down' and perhaps 'command and control' project at the start to a more collaborative project. As the LTIM program matured the water managers have progressively moved towards coordinated larger-scale environmental watering actions across the southern connected basin linking three Areas (e.g. CEWO, 2019c) and there is the opportunity to reflect more on the outcomes of previous actions and use learning from a number of different Areas to support these larger scale actions. To facilitate the sharing of knowledge the CEWO could implement recommendation 4 from the Hart and Butcher (2018) review "that a LTIM Project Steering Committee be established, consisting of the CEWO, CEWO Delivery Teams, Selected Area Team Leads and the MDFRC Director. CEWO should also consider whether the MDBA should also be invited to join this Committee" and recommendation 2 "...that the monitoring and evaluation process needs to be modified to ensure the adaptive management can be undertaken at this large scale".

Consistent with previous documented studies of social learning in environmental water management (e.g. Allan et al., 2009; Allan \& Watts, 2018; Watts et al., 2010; Webb et al., 2018), the LTIM Adaptive Management Forum identified several key factors that are necessary to support exchange of learning and adaptive environmental water management:

- Trusted relationships between scientists, managers, land holders and other community members is critical to enabling adaptive management. Understanding the role of relationship building and consideration of this aspect in resourcing (time, effort, funding) is essential.

- Clear documentation, interpretation and communication of the processes to deliver environmental watering actions and outcomes is important, and would improve transferability. Conversely, poor documentation is a barrier to continued improvement, collective learning and wider dissemination. Improved documentation of effective environmental water planning and use and adaptive management was identified as a target for future improvement in the LTIM program.

This article is protected by copyright. All rights reserved. 
- Monitoring and evaluation teams should include a 'reflector' in the project team, whose primary role would be to examine how adaptive management was working within a project (Webb et al., 2018). This should be considered a separate task to the undertaking of the monitoring and evaluation of ecosystem responses to environmental water.

The five-year LTIM program was completed in 2019 and the Australian government has committed to continuing the monitoring, evaluation and research of environmental water until 2022 (CEWO, 2019a). Drawing on the lessons learned from the LTIM program and the recommendations in the Hart and Butcher (2018) review, the new extended program has received increased funding for engagement and communications, providing support for continued sharing of learnings across the program.

Large-scale monitoring and adaptive management of environmental water is in its infancy and there is potential to improve environmental, social and economic outcomes from environmental water. One of the aims of this analysis and review of the LTIM program was to document the processes for social learning and the adaptive management of environmental water in the Murray-Darling Basin to inspire other water managers to reflect on, and better document, their processes for learning and adaptive management. Through documenting our learning we hope to inspire others to undergo a similar review of their learning processes, and thus increase the rate of adaptive learning and help improve environmental flows programs elsewhere in Australia and the world. With improved processes to increase reflection, documentation and sharing of learnings, there is an opportunity to achieve better environmental outcomes from environmental water.

\section{Data Availability Statement}

Data sharing is not applicable to this article as no new data were created or analysed in this study.

\section{References}

Acreman, M. C., \& Ferguson, A. J. D. (2010). Environmental flows and the European Water Framework Directive. Freshwater Biology, 55, 32-48.

Allan, C., \& Stankey, G. H. (2009). Synthesis of lessons. In C. Allan \& G. Stankey (Eds.), Adaptive environmental management: A practitioners guide. (pp 341-346). Dordrecht, Springer.

Allan, C., \& Watts, R. J. (2018). Revealing adaptive management of environmental flows. Environmental Management, 61, 520-533.

Allan, C., Watts, R. J., Commens, S., \& Ryder, D. S. (2009). Using adaptive management to meet multiple goals for flows along the Mitta Mitta River in south-eastern Australia. In C. Allan \& G. Stankey (Eds.), Adaptive environmental management: A practitioners guide. (pp 59-69). Dordrecht, Springer.

This article is protected by copyright. All rights reserved. 
Australian Government (2007). Water Act 2007 (with Amendments). Canberra, ACT: Australian Government, Office of Parliamentary Counsel.

Australian Government (2012a). Water Act 2007-Basin Plan 2012, Extract for the Federal Commonwealth Register of Legislative Instruments (28 November 2012). Canberra, ACT: Australian Government Office of Parliamentary Counsel.

Australian Government (2012b). Explanatory Statement: Basin Plan 2012. https://www.legislation.gov.au/Details/F2012L02240/Explanatory\%20Statement/Text

Banks, S.A., \& Docker, B.B. (2014) delivering environmental flows in the Murray-Darling Basin (Australia) - legal and governance aspects. Hydrological Sciences Journal, 59, 688-699.

Brisbane Declaration (2007). The Brisbane Declaration. International Water Centre. Retrieved from http://www.watercentre.org/news/declaration.

Brandis, K., Ryall, S., \& Kingsford, R.T. (2011). Lowbidgee 2010/2011 Colonial Waterbird Breeding. Australian Wetland and Rivers Centre, University of New South Wales, Sydney.

Commonwealth of Australia (2011). The importance of water reform in the Murray-Darling Basin. Department of Sustainability, Environment, Water, Population and Communities, Canberra.

Commonwealth Environmental Water (2011). A framework for determining Commonwealth environmental water use. Commonwealth Environmental Water Office, Canberra.

Commonwealth Environmental Water Office (2019a). Monitoring Evaluation and Research Program. https://www.environment.gov.au/water/cewo/monitoring/mer-program

Commonwealth Environmental Water Office (2019b). Commonwealth Environmental Water Office. https://www.environment.gov.au/water/cewo

Commonwealth Environmental Water Office (2019c). Southern Spring flow 2019 fact sheet. https://www.environment.gov.au/water/cewo/publications/southern-spring-flow-2019fact-sheet

Davies, P. E., Harris, J. H., Hillman, T. J., \& Walker, K. F. (2008). SRA Report 1: A Report on the Ecological Health of Rivers in the Murray-Darling Basin, 2004-2007. Prepared by the Independent Sustainable Rivers Audit Group for the Murray-Darling Basin Ministerial Council.

Department of Environment and Energy (2019). Long term Intervention Monitoring Project. Australian Government Department of Environment and Energy. Commonwealth of Australia. Retrieved from https://www.environment.gov.au/water/cewo/monitoring/ltimproject

This article is protected by copyright. All rights reserved. 
Docker, B., \& Robinson, I. (2014). Environmental water management in Australia: experience from the Murray-Darling Basin. International Journal of Water Resources Development, 30:1, 164177 ,

Dudgeon, D., Arthington, A. H., Gessner, M. O., Kawabata, Z., Knowler, D. J., Lévêque, C. ... \& Sullivan, C. A. (2006). Freshwater biodiversity: importance, threats, status and conservation challenges. Biological Reviews, 81,163-182.

Dyer, F., Broadhurst, B., Tschierschke, A., Thiem, J., Thompson, R., Driver, P., ... \& Walcott, A. (2016). Commonwealth Environmental Water Office Long Term Intervention Monitoring Project: Lower Lachlan river system Selected Area 2015-16 Monitoring and Evaluation Synthesis Report. Commonwealth of Australia, 2016.

Dyer, F., Broadhurst, B., Tschierschke, A., Thiem, J., Thompson, R., Bowen, S., ... \& Lenehan, J. (2017). Commonwealth Environmental Water Office Long Term Intervention Monitoring Project: Lower Lachlan river system Selected Area 2016-17 Monitoring and Evaluation Report. Commonwealth of Australia, 2017.

Eberhard, R., Robinson, C. J.,Waterhouse, J., Parslow, J., Hart, B., Grayson, R., \& Taylor, B. (2009). Adaptive management forwater quality planning - from theory to practice. Marine and Freshwater Research, 60, 1189-1195.

Gawne, B., Brooks, S., Butcher, R., Cottingham, P., Everingham, P., Hale, J., ... \& Stoffels, R. (2013). Long Term Intervention Monitoring Logic and Rationale Document. Final Report Prepared for the Commonwealth Environmental Water Office. The Murray-Darling Freshwater Research Centre.

Gawne, B., Hale J., Stewardson, M. J., Webb, J. A., Ryder, D. S., Brooks, S. S., ... \& Wyndham, T. (this issue). The Commonwealth Environmental Waterholder's Long-Term Intervention Monitoring Project: Monitoring environmental flow outcomes in the Murray-Darling Basin, Australia. River Research and Applications.

GBCMA. 2017. Goulburn River seasonal watering proposal 2017-2018. Goulburn Broken Catchment Management Authority, Shepparton.

Harwood, A., Johnson, S., Richter, B., Locke, A., Xuezhong, Y., \& Tickner, D. (2017). Listen to the river: lessons from a global review of environmental flow success stories. WWF-UK, Woking, UK.

Hart, B.T., \& Butcher, R. (2018). Commonwealth Long-Term Intervention Monitoring Project: Stage 1 Mid-Term Review and Evaluation. Report by Water Science Pty Ltd and Water's Edge Consulting for Commonwealth Environmental Water Office, Canberra, 151 pp.

Holling, C. S. (1978). Adaptive Environmental Management and Assessment. Chichester, U.K., Wiley. 
Hutton, D. (2017). Edward-Wakool Aerators: a community initiated response to fish deaths. Western Murray Land Improvement Group Inc., Barham.

Kingsford, R. (2000). Ecological impacts of dams, water diversions and river management on floodplain wetlands in Australia. Austral Ecology, 25(2), 109-127.

Kingsford, R.T., \& Thomas, R.F. (2004) Destruction of wetlands and waterbird populations by dams and irrigation on the Murrumbidgee River in arid Australia. Environmental Management 34(3), 383-396.

Le Quesne, T., Kendy, E., \& Weston, D. (2010). The implementation Challenge: taking stock of government policies to protect and restore environmental flows. The Nature Conservancy \& WWF

McFadden, J. E., Hiller, T. L., \& Tyre, A. J. (2011). Evaluating the efficacy of adaptive management approaches: Is there a formula for success? Journal of Environmental Management, 92, 1354-1359.

MDFRC. (2011). A Review of River Ecosystem Condition in the Murray-Darling Basin. Murray-Darling Freshwater Research Centre, Publication 01/2011

New South Wales Office of Environment and Heritage (2018) Long Term Water Plans. NSW Office of Environment and Heritage. Retrieved from https://www.environment.nsw.gov.au/topics/water/water-for-the-environment/planningand-reporting/long-term-water-plans

Pahl-Wostl, C., Kabat, P., \& Möltgen, J. (Eds.) (2010). Adaptive and integrated water management: coping with complexity and uncertainty. Berlin, Springer.

Peat, M., Moon, K., Dyer, F., Johnson, W., \& Nichols, S. J. (2017). Creating institutional flexibility for adaptive water management: insights from two management agencies. Journal of Environmental Management, 202, 188-197.

Reed, M. S., Evely, A. C., Cundill, G., Fazey, I., Glass, J., Laing, A., ... \& Stringer, L. C. (2010). What is social learning? Ecology and Society, 15:r1

Skinner, D., \& Langford, J. (2013). Legislating for sustainable basin management: the story of Australia's Water Act (2007). Water Policy, 15, 871-894.

South Australian Department for Environment and Water (2017) Environmental Water Planning. Retrieved from https://www.environment.sa.gov.au/topics/river-murray/improving-riverhealth/environmental-water/environmental-water-planning

Southwell, M., Wilson, G., Ryder, D., Sparks, P., \& Thoms, M. (2015). Monitoring the ecological response of Commonwealth Environmental Water delivered in 2013-14 in the Gwydir River

This article is protected by copyright. All rights reserved. 
system. Report prepared by University of New England and North West Ecological Services for the Australian Government Department of Environment. Commonwealth of Australia, Canberra.

Swirepik, J. L., Burns, I. C., Dyer, F. J., Neave, I. A., O'Brien, M. G., Pryde, G. M., \& Thompson, R. M. (2016). Establishing Environmental Water Requirements for the Murray-Darling Basin, Australia's Largest Developed River System. River Research and Applications, 32(6), 11531165.

Walker, K. F. (1992). The River Murray, Australia: A semiarid lowland river. In P. Calow \& G. E. Petts (Eds.), The rivers hanbook (1st ed., Vol. 1, pp. 472-492). Boston: Blackwell Scientific Publishers.

Warner, A. T., Bach, L. B., \& Hickey, J. T. (2014). Restoring environmental flows through adaptive reservoir management: planning, science, and implementation through the Sustainable Rivers Project. Hydrological Sciences Journal, 59, 770-785.

Watts, R.J., McCasker, N., Thiem, J., Howitt, J.A., Grace, M., Kopf, R.K., Healy, S., Bond, N. (2015). Commonwealth Environmental Water Office Long Term Intervention Monitoring Project: Edward-Wakool Selected Area Technical Report, 2014-15. Institute for Land, Water and Society, Charles Sturt University, Prepared for Commonwealth Environmental Water.

Watts, R. J., Kopf, R. K., McCasker, N., Howitt, J. A., Conallin, J., Wooden, I., \& Baumgartner, L. (2018). Adaptive management of environmental flows: using irrigation infrastructure to deliver environmental benefits during a large hypoxic blackwater event in the southern MurrayDarling Basin, Australia. Environmental Management, 61, 469-480.

Watts, R. J., Ryder, D. S., Allan, C., \& Commens, S. (2010). Using river-scale experiments to inform the adaptive management process for variable flow releases from large dams. Marine and Freshwater Research, 61, 786-797

Wassens, S., Spencer, J., Wolfenden, B., Thiem, J., Thomas, R., Jenkins, K., ... \& Callaghan, D. (2018). Commonwealth Environmental Water Office Long-Term Intervention Monitoring project Murrumbidgee River system Selected Area evaluation report, 2014-17. Commonwealth of Australia. Canberra.

Webb, J. A., Watts R. J., Allan C, \& Warner A. T. (2017). Chapter 25: Principles for monitoring, evaluation and adaptive management of environmental flows. In A. Horne, J. A. Webb, M. J. Stewardson, B. Richter, \& M. Acreman (eds,) Water for the Environment. (pp. 599-623), London, Elsevier.

Webb, J. A., Watts, R. J., Allan, C., \& Conallin, J. C. (2018). Adaptive management of environmental flows. Environmental Management, 61, 339-346.

This article is protected by copyright. All rights reserved. 
Webb, A., Guo, D., King, E., Treadwell, S., Baker, B., Casanelia, S., ... \& Vietz, G. (2019). Commonwealth Environmental Water Office Long Term Intervention Monitoring Project Goulburn River Selected Area Scientific Report 2017-18. University of Melbourne Commercial: Melbourne.

This article is protected by copyright. All rights reserved. 
Table 1. Summary of indicators monitored through the Long Term Intervention Monitoring Program in seven Selected Areas within the Murray-Darling Basin. Basin-scale indicators (category 1) were monitored across all Areas using standard methods. Optional Basin-scale indicators (category 2) were monitored to inform Basin-scale evaluation and Selected Area evaluation. Local-scale indicators (category 3 ) were monitored to answer questions specific to environmental water delivery in those Areas. + specifies indicators monitored in each Area.

\begin{tabular}{|c|c|c|c|c|c|c|c|c|c|}
\hline \multirow[b]{2}{*}{$\begin{array}{l}\frac{ \pm}{ \pm} \\
\frac{ \pm}{0} \\
\frac{0}{10} \\
\frac{10}{1}\end{array}$} & \multirow[b]{2}{*}{ Indicators monitored } & \multirow[b]{2}{*}{ 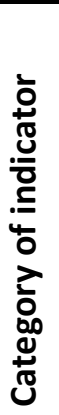 } & \multicolumn{7}{|c|}{ Selected Area } \\
\hline & & & 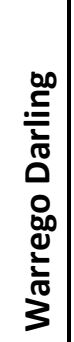 & 豙 & $\begin{array}{l}\frac{c}{\sigma} \\
\frac{\mathrm{T}}{\mathrm{C}} \\
\mathbb{J}\end{array}$ & 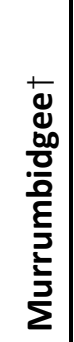 & $\begin{array}{l}\frac{1}{0} \\
\frac{1}{10} \\
\frac{1}{10} \\
\frac{1}{0} \\
\frac{10}{3} \\
\frac{3}{4}\end{array}$ & 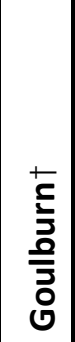 & 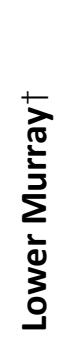 \\
\hline \multirow{16}{*}{ 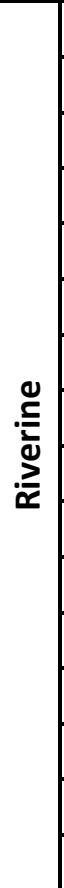 } & Ecosystem diversity & 1 & + & + & + & + & + & + & + \\
\hline & River hydrology & 1 & + & + & + & + & + & + & + \\
\hline & Water quality & 1 & + & + & + & + & + & + & + \\
\hline & Fish community and age structure & 1 & + & + & + & + & + & + & + \\
\hline & Stream metabolism & 2 & & & + & + & + & + & + \\
\hline & Fish spawning & 2 & & + & + & + & + & + & + \\
\hline & Micro invertebrates & 2 & + & + & & + & & & + \\
\hline & Fish movement (acoustic telemetry) & 2 & & + & & & + & + & \\
\hline & Macro invertebrates & 3 & + & + & & & & & \\
\hline & Fish recruitment and growth $\left(0-1^{+}\right)$ & 3 & \multirow{7}{*}{\multicolumn{4}{|c|}{$\begin{array}{l}\text { No Category } 3 \\
\text { monitoring in } \\
\text { river channel }\end{array}$}} & + & & + \\
\hline & Hydraulic modelling & 3 & & & & & + & + & + \\
\hline & Riverbank and aquatic vegetation & 3 & & & & & + & + & \\
\hline & Carbon fluorescence & 3 & & & & & + & & \\
\hline & Algae and nutrients\# & 3 & & & & & + & & \\
\hline & Bank condition & 3 & & & & & & + & \\
\hline & Matter transport & 3 & & & & & & + & \\
\hline \multirow{8}{*}{ 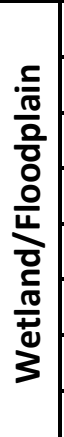 } & Ecosystem diversity & 1 & + & + & + & + & \multirow{8}{*}{\multicolumn{3}{|c|}{$\begin{array}{c}\text { No wetland } \\
\text { or } \\
\text { floodplain } \\
\text { monitoring }\end{array}$}} \\
\hline & Vegetation diversity & 1 & + & + & + & + & & & \\
\hline & Tree condition & 2 & & & + & & & & \\
\hline & Waterbird diversity\# & 2 & + & + & + & + & & & \\
\hline & Waterbird breeding\# & 2 & & + & + & + & & & \\
\hline & Frogs and tadpoles & 3 & + & + & + & + & & & \\
\hline & Inundation mapping & 3 & + & + & + & + & & & \\
\hline & Water quality & 3 & + & + & & + & & & \\
\hline
\end{tabular}




\begin{tabular}{|l|l|l|l|l|l|}
\hline Micro invertebrates & 3 & & + & & + \\
\hline Turtles & 3 & & & & + \\
\hline Fish community & 3 & & & & + \\
\hline
\end{tabular}

† Monitoring of environmental water delivery prior to LTIM program in these Areas

\# Event based monitoring of these indicators

Table 2. Summary of processes for learning and exchange of information to inform adaptive management in each of the seven Selected Areas in the Australian Long-Term Intervention Monitoring program. Ticks $(\checkmark)$ indicate the processes that each Area Teams used to facilitate inner loop and main loop learning.

\begin{tabular}{|c|c|c|c|c|c|c|c|}
\hline \multirow[b]{2}{*}{$\begin{array}{l}\text { Processes to support learning and exchange of } \\
\text { information }\end{array}$} & \multicolumn{7}{|c|}{ Selected Areas } \\
\hline & 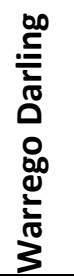 & 亥 & $\begin{array}{l}\frac{c}{\pi} \\
\frac{\pi}{c} \\
\frac{J}{J}\end{array}$ & 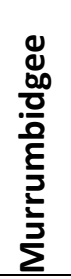 & $\begin{array}{l}\overline{8} \\
\frac{8}{10} \\
\frac{1}{10} \\
\frac{1}{1} \\
\frac{1}{0} \\
\frac{3}{0} \\
\frac{3}{0}\end{array}$ & 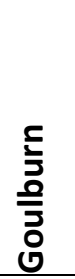 & 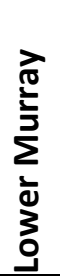 \\
\hline \multicolumn{8}{|c|}{ Inner Loop learning: Learning informing water delivery during watering actions } \\
\hline Project team meetings & $\checkmark$ & $\checkmark$ & $\checkmark$ & $\checkmark$ & $\checkmark$ & $\checkmark$ & $\checkmark$ \\
\hline Planned meetings with environmental water managers & $\checkmark$ & $\checkmark$ & $\checkmark$ & $\checkmark$ & $\checkmark$ & & $\checkmark$ \\
\hline Additional informal meetings with water managers & $\checkmark$ & $\checkmark$ & $\checkmark$ & $\checkmark$ & $\checkmark$ & $\checkmark$ & $\checkmark$ \\
\hline Community meetings during water delivery & & & & & $\checkmark$ & & \\
\hline \multicolumn{8}{|c|}{ Main Loop learning: Contribution to annual and long-term goals and plans in response to learning } \\
\hline Meetings with environmental water managers & $\checkmark$ & $\checkmark$ & $\checkmark$ & $\checkmark$ & $\checkmark$ & $\checkmark$ & $\checkmark$ \\
\hline Environmental Water Advisory Groups & $\checkmark$ & $\checkmark$ & $\checkmark$ & $\checkmark$ & $\checkmark$ & & $\checkmark$ \\
\hline Annual environmental water planning workshops & $\checkmark$ & $\checkmark$ & $\checkmark$ & $\checkmark$ & $\checkmark$ & $\checkmark$ & $\checkmark$ \\
\hline $\begin{array}{l}\text { Workshops to develop long-term environmental water } \\
\text { plans }\end{array}$ & $\checkmark$ & $\checkmark$ & $\checkmark$ & $\checkmark$ & $\checkmark$ & $\checkmark$ & $\checkmark$ \\
\hline
\end{tabular}


Table 3. Summary of processes for learning and exchange of information to inform adaptive management among Selected Areas in the Australian Long-Term Intervention Monitoring program. Shaded rectangles indicate Areas that participated in shared activities to support outer loop learning and exchange of information.

\begin{tabular}{l}
\hline Processes to support outer loop learning and \\
exchange of information among Areas
\end{tabular}

This article is protected by copyright. All rights reserved. 


\section{Figure legends}

Figure 1. Map of the Murray-Darling Basin in eastern Australia showing location of seven Selected Areas where the monitoring has been undertaken as part of the Australian governments' Long Term Intervention Monitoring program.

Figure 2. The adaptive management cycle showing the main learning cycle where lessons inform the next formal phase of planning and implementation. The inner learning loops (solid curved arrows) are small changes that are made based on learnings that occur between major planning reviews. The outer learning loops (dashed curved arrows) are learnings that are shared with practitioners and stakeholders that are external to the project (Modified from Webb et al. 2017 and Allan and Watts 2018).

This article is protected by copyright. All rights reserved. 


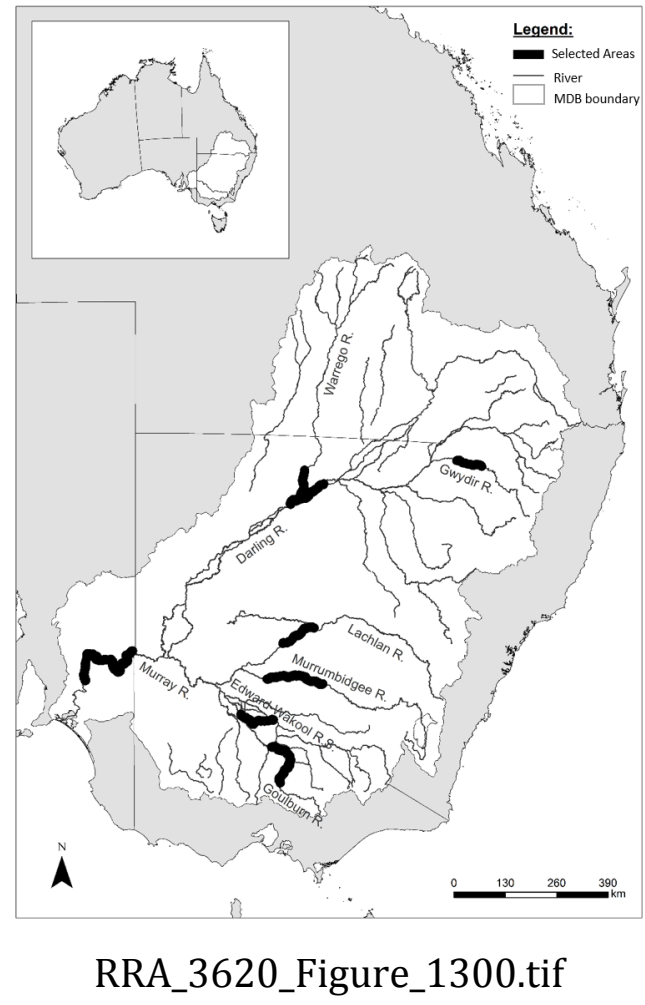

This article is protected by copyright. All rights reserved. 
Inner Learning Loops:

Learning undertaken during each main learning cycle by stakeholders directly involved in the project. Small changes to strategies, plans, environmental watering actions and monitoring are made within the watering year in response to learnings
Main learning cycle:

Annual and long-term environmental

watering plans and long-term monitoring

plans are reviewed and modified in

response to learnings at the end of each

plan-do-monitor-learn cycle

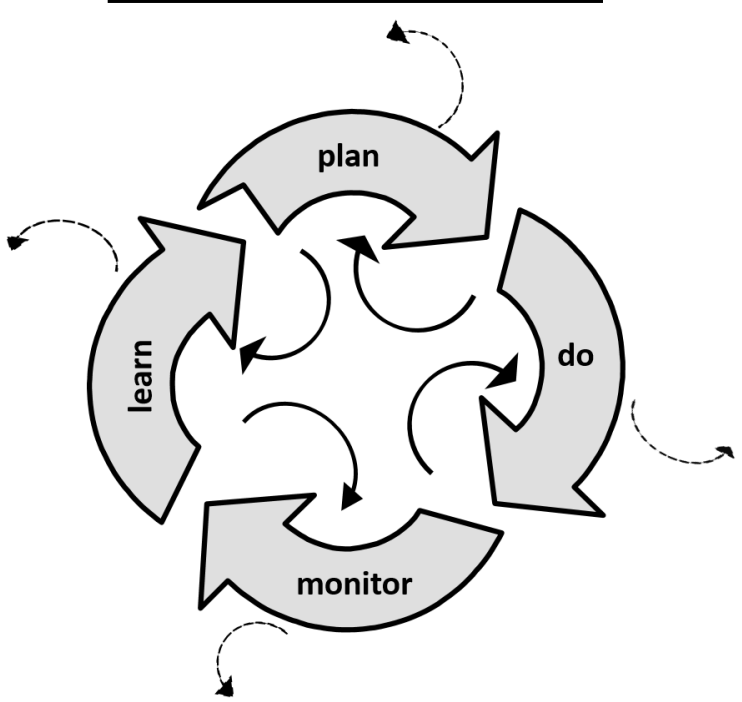

RRA_3620_Figure_2300.tif
Outer Learning Loops:

Innovations and learnings from the project are shared with practitioners and stakeholders who are not directly involved in the project and may be external to the project 


\section{University Library}

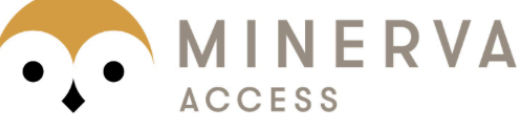

A gateway to Melbourne's research publications

Minerva Access is the Institutional Repository of The University of Melbourne

Author/s:

Watts, RJ;Dyer, F;Frazier, P;Gawne, B;Marsh, P;Ryder, DS;Southwell, M;Wassens, SM;Webb, JA;Ye, Q

Title:

Learning from concurrent adaptive management in multiple catchments within a large environmental flows program in Australia

Date:

2020-05-01

Citation:

Watts, R. J., Dyer, F., Frazier, P., Gawne, B., Marsh, P., Ryder, D. S., Southwell, M., Wassens, S. M., Webb, J. A. \& Ye, Q. (2020). Learning from concurrent adaptive management in multiple catchments within a large environmental flows program in Australia. RIVER RESEARCH AND APPLICATIONS, 36, (4), pp.668-680. WILEY. https://doi.org/10.1002/ rra.3620.

Persistent Link:

http://hdl.handle.net/11343/275602 